\title{
Triangular Waveguide Fed Slot Antenna
}

\author{
Shraddha J. Salve' ${ }^{1}$ J. K. Prajapati ${ }^{2}$, S. S. Kakatkar ${ }^{3}$, S. L. Nalbalwar ${ }^{4}$ \\ Student, Electronics \& Telecommunication Department, Dr. BATU, Lonere, Raigad, India ${ }^{1}$ \\ Scientist, AMS Division, SAMEER, Mumbai, India ${ }^{2}$ \\ Scientist, Head of AMS Division, SAMEER, Mumbai, India ${ }^{3}$ \\ Professor, Head of Electronics \& Telecommunication Department, Dr. BATU, Lonere, Raigad, India ${ }^{4}$
}

\begin{abstract}
Limited literature is available on triangular waveguides and triangular waveguide fed slot antennas, as compared to their rectangular and circular waveguide counterparts. In this paper, simulated and measured results have been presented for a right angled isosceles triangular waveguide fed slot antenna in $\mathrm{S}$ band. The antenna has been simulated and then fabricated in aluminium material. Simulated and experimental results show good agreement in resonant frequency. This work can be used in the design of a triangular waveguide fed low cost slot array.
\end{abstract}

Keywords: Antenna, Slot antenna, Triangular waveguide, Waveguide

\section{INTRODUCTION}

Although waveguide fed slot antennas have been used and analyzed extensively over the past few decades, not much literature is available on triangular waveguide fed slot antennas, mainly because of the complexity in their analysis as compared to the rectangular and circular waveguide fed slot antennas. Slot array antennas typically have the advantage of high directivity, low power loss, high power handling capacity, low attenuation and immunity against any RF interference inside the waveguide. The basic theory of slots has been well explained and the analysis of longitudinal slots has been presented in [1-6]. An excellent review of waveguide fed slot antennas is available in [7-8].

Triangular waveguide fed slot antennas have recently been discussed in [9-10]. The design requires mode analysis of triangular waveguides to identify the dominant modes. Modes in triangular waveguides have been discussed in [11]. For right angled isosceles triangular waveguide, the lowest order cutoff waveguide number has been computed [12]. According to this paper, the dominant mode is $\mathrm{TE}_{10}$ and the second cutoff occurs at 1.414 times dominant mode cutoff frequency and the third cutoff at 2 times of dominant mode cutoff frequency for isosceles right angle triangular waveguide. Also, TE and TM mode equations have been given for different triangular waveguides [12]. Impedance of the triangular waveguides is quite close to that of rectangular waveguides. Simulation of isosceles triangular waveguide with different vertex angles has been done [11]. When the vertex angle $\alpha<60^{\circ}$, the e-field distribution is more at the vertex and $\mathrm{TE}_{01}$ mode propagates through the waveguide. When $\alpha>60^{\circ}$, the e-field distribution is more at the base of the triangular waveguide and $\mathrm{TE}_{10}$ mode propagates through waveguide. Here, in the present paper, the vertex angle has been kept $90^{\circ}$ and $\mathrm{TE}_{10}$ mode has been excited.

Simple and inexpensive technique has been used to form a triangular waveguide fabricated out of sheet metal using folding [9-10]. Although some gap is left due to simply bending the sheet, the gap leakage is about $-2.5 \mathrm{~dB}$ for $\mathrm{TE}_{01}$ mode and for $\mathrm{TE}_{10}$ is below $-40 \mathrm{~dB}$. So, the designed slot array is low cost and has been shown to give good performance [9]. Open ended triangular waveguide antenna has been used as a phased array antenna element for wide angle scanning applications and arranged in a compact configuration [14].

This paper presents the design, fabrication and measurement of isosceles right angled triangular waveguide fed slot antenna in S-band. The waveguide in [9] has one of its edges open and in [10] one of the edges has been sealed using aluminium tape, as the waveguide has been fabricated from sheet metal using folding. In this paper, the side remaining after folding two sides has been welded and the waveguide has been completely closed from the sides. Also, the percentage slot offset is more than that in [10] where the corners have also been rounded. The antenna proposed in this paper has been simulated and has then been fabricated. The simulated and measured results have been compared in Section III and show good agreement. The Triangular waveguide fed slot antenna is more compact than a square waveguide and can be fabricated at a lower cost from sheet metal as compared to a rectangular waveguide [15]. 


\section{DESIGN AND SIMULATION}

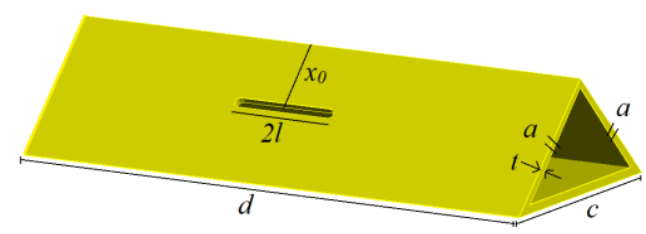

Fig. 1(a) Triangular waveguide fed longitudinal slot

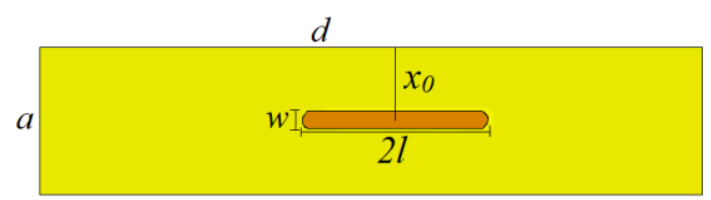

Fig. 1(b) Slot parameters (front-view)

The triangular waveguide fed slot has been shown in fig. 1(a). In Fig. 1(a), a is the length of the identical sides of the isosceles triangular waveguide. $d$ is the total length of the waveguide. The waveguide has been fed using a wire probe at one end and terminated at the other end in a similar manner. The distance between the two ports is approximately two times of $\lambda_{\mathrm{g}}$, where $\lambda_{\mathrm{g}}$ is the guide wavelength in triangular waveguide which is calculated with the help of $\lambda_{\mathrm{o}}$ and a, as,

$$
\lambda_{g}=\frac{\lambda_{o}}{\sqrt{1-\left[\frac{\lambda_{o}}{2 a}\right]^{2}}}
$$

Both the ends of the triangular waveguide have been shorted. Offset from the vertex to the centre of the slot is $\mathrm{x}_{0}$ as shown in Fig. 1(b). Length of the slot is 21 and the width of the slot w has been kept less than one-tenth of the length i.e. $w<21 / 10$. Since the fabricated milled slot would be having rounded ends, a rounded end slot was used for simulation. Probe length and back-short distance from the probe have been optimized for the desired frequency. The probe length and probe thickness are inversely proportional to the resonant frequency. Initially, probe length has been optimized, and then back-short wall has been tuned for better bandwidth. Slot length has been increased in steps in simulation and has been tuned to the desired resonant frequency. A waveguide of dimensions a $=88 \mathrm{~mm}, c=124.5 \mathrm{~mm}$ and thickness $\mathrm{t}=6 \mathrm{~mm}$ has been used in simulation. The cutoff frequency for this waveguide calculated from $\lambda_{\mathrm{c}}=2 \mathrm{a}$ is $1.7 \mathrm{GHz}$ and the cutoff for the second higher order mode is $2.4 \mathrm{GHz}$. In simulation, the offset $\mathrm{x}_{0}$ was chosen to be $44 \mathrm{~mm}$ i.e. at the centre of the side of dimension $88 \mathrm{~mm}$. The slot length 21 giving best results was then chosen.

The resonant frequency of the slot has been determined from the relative transmission co-efficient phase following the procedure for transmission measurement similar to that given in [15]. Relative transmission coefficient is the ratio of the complex transmission coefficient with the slot open to that when the slot is completely covered [15]. As shown in Fig.2, measured and simulated curves for the relative transmission coefficient phase cross the $0^{\circ}$ phase at a particular frequency, which is the resonant frequency of the slot. The reactance part of relative transmission coefficient becomes zero and the slot becomes purely resistive at $0^{\circ}$ phase crossover which is the resonant frequency. For a required resonant frequency of $2.18 \mathrm{GHz}$, the resonant slot length was found to be $71 \mathrm{~mm}$ for a slot width of $\mathrm{w}=7 \mathrm{~mm}$. The simulated magnitude of $S_{21}$ was found to be $-5.35 \mathrm{~dB}$ at a resonant frequency of $2.18 \mathrm{GHz}$ as shown in Fig.3.

\section{RESULTS AND DISCUSSION}

The triangular waveguide fed slot antenna has been fabricated as per the simulated results. Aluminium $90^{\circ}$ angle has been used for the fabrication of waveguide which has been chamfered by $45^{\circ}$ at both the edges and milled for smoothness. Then, a metal plate has been welded to close the angle and form a right angled triangular waveguide. Waveguide has thickness of $6 \mathrm{~mm}$ as shown in Fig. 1(a). A plunger has been used to adjust the distance between port and the back-short wall so that the VSWR is minimum over the band of operation from 2-2.4GHz. The slot has been milled in one of the perpendicular sides of the waveguide and has been located at the centre of that side as shown in fig. 1(b). Practically, the slot has rounded ends due to milling. The experimental results have been taken. The S-parameters have been measured by VNA. Fig 2 . shows the $0^{\circ}$ phase crossover at resonant frequencies for simulated and measured results. Phase of $S_{21}$ of the waveguide without slot is stored and phase of $S_{21}$ of the waveguide having slot is divided by the stored value of $S_{21}$ to get the relative transmission coefficient. Resonant frequency for simulated slot was $2.18 \mathrm{GHz}$ and for measured slot was found to be $2.167 \mathrm{GHz}$ with less than $1 \%$ mismatch between the two as shown in Fig.2. 


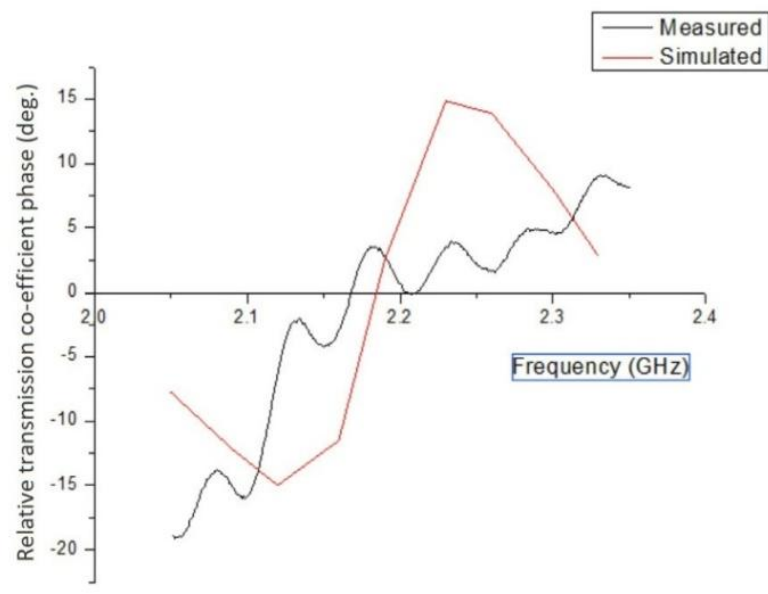

Fig.2. Relative Phase Plot $\left(\mathrm{S}_{21}\right.$ with slot/S $\mathrm{S}_{21}$ without slot $)$

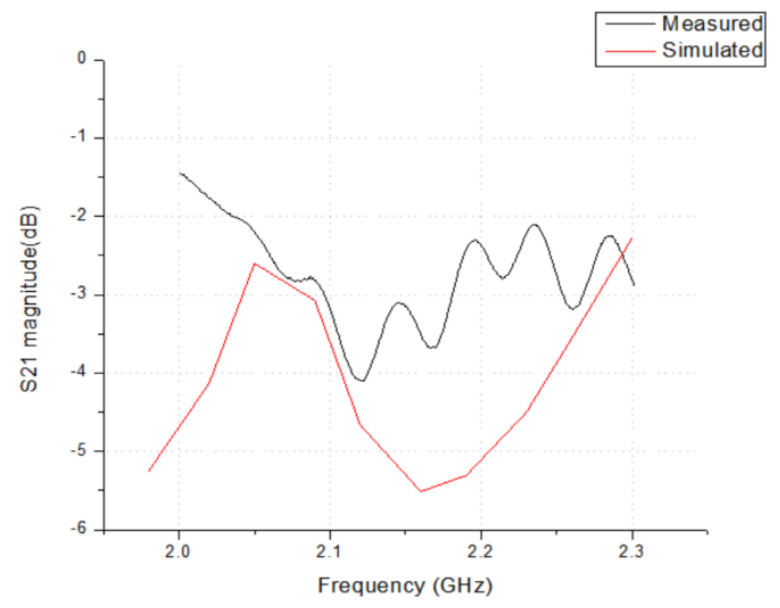

Fig.3. Magnitude of S21

Figure 4 shows the measured and simulated magnitude of transmission coefficient $S_{21}$. Simulated slot gives magnitude $S_{21}$ as $-5.35 \mathrm{~dB}$ and measured one gives $-3.7 \mathrm{~dB}$. The difference in $\mathrm{S}_{21}$ could be due to the finite reflection of the probes which could not be calibrated out because of the non-standard shape of the waveguide, gap between shorting plunger and waveguide, fabrication tolerances due to deformation during welding as the waveguide has been fabricated from an L-bend to which a plate has been welded, waveguide losses and surface roughness.

\section{CONCLUSION}

A triangular waveguide fed slot antenna has been designed and fabricated. The waveguide is completely closed on all the three sides and has all straight sides. Simulated and measured resonant frequencies are in good agreement. This antenna is more compact than the corresponding square waveguide and can be fabricated at a lower cost from sheet metal.

\section{ACKNOWLEDGEMENT}

The authors are thankful to Dr. Sulabha Ranade, Director General, SAMEER and all the scientific personnel of AMSD division, GFD division, SAMEER for their encouragement and support for this work.

\section{REFERENCES}

[1]. A.F Stevenson, "Theory of Slots in Rectangular Wave Guides", Journal of Applied Physics, 1948.

[2]. L.G.Josefsson, "Analysis of longitudinal slots in rectangle waveguides", IEEE Trans. Antennas Propagat, vol.AP-35, pp.1351-1357, Dec.1987

[3]. A. A. Oliner, "The impedance properties of narrow radiating slots in the broad face of rectangular waveguide Part II: Comparison with measurement”, IRE Trans. Antennas Propagat., vol. AP-5, pp.12-20, Jan. 1957.

[4]. G. J. Stern, R. S. Elliott, "Resonant length of longitudinal slots and validity of circuit representation: Theory and experiment", IEEE Trans. Antennas Propagat., vol. AP-33, pp. 1264-1271, Nov. 1985. 
[5]. T. V. Khac, C. T. Carson, "Impedance properties of a longitudinal slot antenna in the broadface of rectangular waveguide", IEEE Trans. Antennas Propagat., vol. AP-21, pp. 708-710, 1973.

[6]. S. S. Kakatkar, Amit Deshmukh, Dr. K. P. Ray, "Internal admittance elements of a rectangular waveguide longitudinal slot using the image method", Electromagnetics, pp. 1-19, doi: 10.1080/02726343.2019.1619230. (Published Online). May 2019.

[7]. S.R.Rengarajan, L.G.Jossefson, R.R.S.Elliot," Waveguide-fed slot antennas \& arrays: A review", Electromagnetics, vol.19, no.1, pp.3-22, 1999.

[8]. V. V. S. Prakash, S. Christopher, “A selective survey of the Waveguide-Fed Slot Radiators”, IETE Technical Review, Vol.17 nos. 1\&2, pp. 5159, April 2000.

[9]. Ying Chen, R.G. Vaughan, "Slot antenna array on triangular waveguide", Antennas and Propagation USNC/URSI National Radio Meeting 2015 IEEE International Symposium on, pp. 206-207, 19-24 July 2015.

[10]. Ying Chen, Sae-Won Lee, Rodney G. Vaughan, "Self-assembled triangular waveguide slot array for system-on-chip applications", IET Microwaves Antenna and Propagation, vol. 11, Issue 14, p. 2035-2042, 19 Nov. 2017.

[11]. Y. Chen, R. G. Vaughan, "Mode and characteristic impedance of isosceles triangular waveguide", Proceedings of 16th Antenna Technology and Applied Electromagnetics, pp. 13-16, July 2014.

[12]. P. L. Overfelt and D. J. White,'TE and TM modes of Some Triangular CrossSection Waveguides Using Superposition of Plane Waves", IEEE Trans. Microwave Theory Tech., vol. MTT-34, pp. 161-167, Jan. 1986.

[13]. M. Simeoni, M. Jofre, "Equilateral triangular waveguide antenna - a spectral domain analysis", IET Microwaves Antennas and Propagation, vol. 4, no. 3, pp. 296-304, March 2010.

[14]. M. Simeoni, M. C. Vigano, I. E. Lager,'Open-ended triangular waveguide antenna”, Antennas and Propagation Society International Symposium, 2008. AP-S 2008. IEEE, vol., no., pp. 1, 4, 5-11 July 2008.

[15]. R. Shavit, R. S. Elliott (1983), "Deign of an array of transverse slots fed by a boxed stripline," IEEE Transactions on Antennas and Propagation, 31(4), 545-552.

[16]. (2018). FEKO software, trial version, EM Software and Systems. Available: www.feko.info

\section{BIOGRAPHIES}

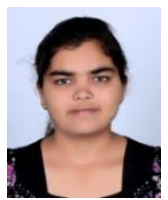

Shraddha J. Salve received B.E. Degree in Electronics and Telecommunication Engineering from Government College of Engineering and Research, Avasari Khurd, in 2017 and currently, pursuing M.Tech Degree in Electronics and Telecommunication Engineering from Dr. Babasaheb Ambedkar Technological University, Lonere. Her interest includes antenna analysis and design.

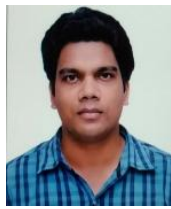

J. K. Prajapati received the B.Tech Degree in Electronics and Communication Engineering from GLA Institute of Technology and Management, Mathura, UP in 2010. He joined Society for Applied Microwave Electronics Engineering and Research (SAMEER) in year 2012 and currently he is working as a Scientist in Atmospheric Microwave System Division (AMSD) of SAMEER Mumbai. He has been working in the areas of RF and Microwave systems/components and in the design of antenna elements/arrays. He has authored and co-authored 3 research papers. His interests include electromagnetic theory and antenna analysis and design.

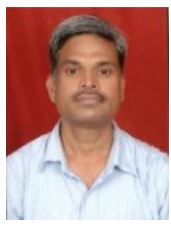

S. S. Kakatkar received the B.E Degree in Electronics and Telecommunication Engineering from College of Engineering, Pune (COEP) and M. Tech Degree in Electronics and Electrical Comm. Engg with specialization in Microwave Engineering from Indian Institute of Technology, Kharagpur, India in 1991. He joined Society for Applied Microwave Electronics Engineering and Research (SAMEER) in the same year and currently, he is in the Head of Atmospheric Microwave System Division (AMSD) of SAMEER, Mumbai. He has been working in the areas of RF and microwave systems/components and in the design of antenna elements/arrays, high power RF/microwave sources for industrial applications and EMI/EMC. He has authored and co-authored more than 50 research papers in international peer-reviewed journals and conferences. His interests include electromagnetic theory and antenna analysis and design.

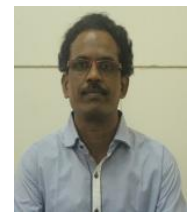

S. L. Nalbalwar received B. E(CSE) and M.E(Electronics Engg.) Degree from SGGSC E\&T Nanded in 1990 and 1996 respectively and received the Ph.D. in E\&TC from IIT Delhi in 2008. Currently, he is working as Professor \& Head of the department of E\&TC engineering at Dr. Babasaheb Ambedkar Technological University, Lonere, Raigad. His area of interest includes signal processing. He has various publications which include 100 international journal, 50 national journals, 70 international conferences and 50 national conferences. He has also published books in signals \& systems, basic electronics and devices and circuits. 